\title{
Efectividad y seguridad comparada de inhibidores del cotransportador sodio-glucosa tipo 2 (iSGLT2) en diabetes mellitus tipo 2: revisión rápida de revisiones sistemáticas y metaanálisis
}

\author{
Comparative effectiveness and safety of Sodium-glucose Cotransporter-2 \\ (SGLT2) inhibitors in type 2 diabetes mellitus: rapid review of systematic \\ reviews and meta-analyzes
}

Chacón $K,{ }^{1}$ Mendivelso F, ${ }^{2}$ Gómez $O,{ }^{3}$ González C, ${ }^{4}$ Pinto $D,{ }^{5}$ Yama E, ${ }^{6}$ Moscoso E, ${ }^{7}$ Acevedo JR, ${ }^{8}$ Bohórquez LF, Rincón O, ${ }^{10}$ Ruiz PC, ${ }^{11}$ Espitia Malagón RA, ${ }^{12}$ Isaza $M,{ }^{13}$ Aroca $G,{ }^{14}$ Tovar $H,{ }^{15}$ Luján $D,{ }^{16}$ Rodríguez $M,{ }^{17}$ Hamann $O,{ }^{18}$ Yomayusa $N .{ }^{19}$

${ }^{1}$ Ft. MSc epidemiología clínica. Instituto Global de Excelencia Clínica (IGEC), Keralty. Bogotá, Colombia.

${ }^{2} M D$, cirujano. Esp., Msc, MPH, FETP, IGEC. Bogotá, Colombia. ${ }^{3} M D$, especialista en medicina familiar, IGEC, Keralty. Profesor asociado, Universidad del Bosque. Bogotá, Colombia.

${ }^{4} \mathrm{MD}$, especialista en medicina interna y nefrología, magíster en epidemiología, Clínica Universitaria Colombia, Hospital Universitario San Ignacio. Bogotá, Colombia.

${ }^{5} \mathrm{MD}$, especialista en medicina interna, coordinador, posgrado en medicina interna, Fundación Universitaria Sanitas, internista adscrito, Oficina Internacional Clínica Universitaria Colombia. Bogotá

${ }^{6} \mathrm{MD}$, especialista en medicina interna, nefrología. Clínica Colsanitas. Bogotá, Colombia.

${ }^{7} M D$, especialista en endocrinología. Coordinador, servicio de endocrinología, Clínica Reina Sofia, Colsanitas. Bogotá, Colombia. ${ }^{8} \mathrm{MD}$, especialista en medicina interna, IGEC. Keralty. Bogotá, Colombia.

${ }^{9} \mathrm{MD}$, especialista en diabetes. Bogotá, Colombia.

${ }^{10} \mathrm{MD}$, especialista en medicina interna, endocrinología y docencia universitaria, unidad de práctica integrada en diabetes, Sanitas. Coordinador, servicio de endocrinología y posgrado en endocrinología, Hospital Militar Central, Universidad Militar Nueva Granada. Bogotá, Colombia.
${ }^{11} M D$, especialista en medicina interna, endocrinología y diabetes. Bogotá, Colombia.

${ }^{12} \mathrm{MD}$, especialista en medicina familiar. Director científico de núcleo norte, Sanitas. Bogotá, Colombia.

${ }^{13} \mathrm{MD}$ familiar, experto en diabetes mellitus. Líder, programa diabetes, Colsanitas, Banco de la República. Bogotá, Colombia.

${ }^{14} \mathrm{MD}$, especialista en nefrología, Asociación Colombiana de Nefrología e Hipertensión Arterial. Bogotá, Colombia.

${ }^{15} \mathrm{MD}$, especialista en medicina interna y endocrinología, Clínica Colsanitas. Bogotá, Colombia.

${ }^{16} \mathrm{MD}$, especialista medicina interna y endocrinología, Asociación Colombiana de Diabetes Bogotá, Colombia.

${ }^{17} \mathrm{MD}$, especialista en medicina interna y nefrología, Asociación Colombiana de Nefrología e Hipertensión Arterial. Bogotá, Colombia.

${ }^{18} \mathrm{MD}$, especialista en medicina familiar integral. Director, programa Medicina Familiar Integral, FUJNC. Presidente, Sociedad Colombiana de Medicina Familiar (SOCMEF). Bogotá, Colombia.

${ }^{19} \mathrm{MD}$, especialista en medicina interna y nefrología. Grupo de investigación traslacional, IGEC, Keralty. Bogotá, Colombia.

Autor de correspondencia: Kelly Rocío Chacón Acevedo Correo electrónico: krchacon@colsanitas.com Fecha de recepción: 03/06/2020

Fecha de aceptación: 10/03/2021 


\section{Resumen}

Objetivo: recopilar y evaluar la evidencia disponible respecto a la efectividad y seguridad comparada de inhibidores del cotransportador de sodio glucosa tipo 2 (iSGLT2) en pacientes con diabetes mellitus tipo 2.

Metodología: se realizó una revisión sistemática rápida de revisiones sistemáticas de iSGLT2 en las bases de datos Medline y Embase hasta septiembre de 2019. El desenlace primario cardiovascular incluyó eventos adversos cardiovasculares mayores (MACE) que corresponden a muerte por causa cardiovascular, ataque cerebrovascular (ACV) no fatal, infarto agudo de miocardio (IAM) no fatal, además de hospitalización por insuficiencia cardíaca; desenlace renal (definido como progresión de enfermedad renal), disminución de la tasa de filtración glomerular (TFG) y de la relación albuminuria-creatinuria. El desenlace de seguridad agrupó hipoglucemia, fracturas, infecciones urinarias, entre otros. La calidad metodológica de las revisiones se evaluó con el instrumento A measurement Tool to Assess Systematic Review (AMSTAR-2) modificado.

Resultados: se incluyeron 5 revisiones sistemáticas de la literatura de calidad media y alta según AMSTAR-2 modificado, entre las cuales se encontró que los iSGLT2 reducen el riesgo de mortalidad cardiovascular en un $23 \%$, de mortalidad por todas las causas en $20 \%$ y en admisión hospitalaria por insuficiencia cardíaca en un 33 \%, en comparación con el cuidado estándar. En cuanto al desenlace renal, los iSGLT2 enlentecen el deterioro de la enfermedad renal y reducen la progresión a albuminuria en pacientes con proteinuria ya documentada. En el desenlace de seguridad se observa una mayor posibilidad de desarrollar infecciones del tracto genitourinario respecto a antidiabéticos orales.

Conclusiones: la evidencia sugiere que los iSGLT2 son efectivos en la reducción del riesgo de mortalidad cardiovascular, de mortalidad por todas las causas, de admisión hospitalaria por insuficiencia cardíaca, de progresión de la nefropatía y del desarrollo de enfermedad renal en estadio final. En desenlaces de seguridad, la evidencia sugiere que los iSGLT2 tienen menor riesgo de eventos de hipoglucemia.

Palabras clave: inhibidores del cotransportador de sodioglucosa 2, diabetes mellitus tipo 2, enfermedades cardiovasculares, enfermedades renales, hipoglucemia.

\section{Abstract}

Aim: To evaluate the evidence of effectiveness and safety of sodium glucose co-transporter inhibitors type 2 (iSGLT2) in patients with type 2 diabetes mellitus.

Methodology: A rapid systematic review of systematic reviews of iSGLT2 was performed in the Medline and Embase databases until September 2019. Cardiovascular outcome was major cardiovascular adverse events (MACE): death due to cardiovascular causes, non-fatal stroke and acute non-fatal myocardial infarction, in addition to hospitalization for heart failure; renal outcome was progression of renal disease, decrease in glomerular filtration rate and albumin-creatinine ratio. The safety outcome comprehended hypoglycemia, fractures, and urinary infections. The methodological quality was evaluated with the modified A measurement Tool to Assess Systematic Review (AMSTAR-2) tool.

Results: Five systematic reviews of the literature of medium and high-quality AMSTAR-2 were included. The iSGLT2 reduces the risk of cardiovascular mortality by 23\%, from all-cause mortality by $20 \%$ and in hospital admission for heart failure in 33\% versus standard care. In addition, the iSGLT2 slows the deterioration of renal disease and reduces the progression to albumin in patients with documented proteinuria. In the safety outcome, there is a greater possibility of developing genitourinary tract infections with respect to oral antidiabetics.

Conclusions: The evidence suggests that iSGLT2 are effective in reducing the risk of cardiovascular mortality, all-cause mortality, hospital admission for heart failure, progression of nephropathy and the development of end-stage renal disease. In safety outcomes, the evidence suggests that iSGLT2 have a lower risk of hypoglycemic events.

Keywords: Sodium-Glucose Transporter 2 Inhibitors; Type 2 Diabetes Mellitus; Cardiovascular Diseases; Kidney Diseases; Hypoglycemia.

\section{Introducción}

La diabetes mellitus tipo 2 (DM2) es una condición crónica de interés para la agenda de salud pública mundial debido a su impacto en la calidad de vida de los pacientes, complicaciones, secuelas y el alto costo sanitario que implica su manejo (1). Según el estudio de carga de enfermedad, en 2016 la DM2 ocupó el cuarto lugar en las causas de discapacidad y el puesto 15 en causas de muerte prematura, y se espera que en 2040 esta condición sea la séptima causa de muerte a nivel mundial (2).

Para 2014, 422 millones de adultos fueron diagnosticados DM2 en el mundo, con una prevalencia entre 4,7 \% y 8,5 \% (1); mientras que en Colombia en 2017 la prevalencia fue de 2,2 \%, siendo en el régimen contributivo, 3,4\% frente al 1,6\% del régimen subsidiado $(3,4)$. En países de bajos ingresos se espera que en 2045 esta condición incremente el 62 \% (4). El gran interés en la DM2 desde las agendas sanitarias mundiales radica en la carga de enfermedad que implica para los sistemas de salud y la calidad de vida de las poblaciones al asociarse con el desarrollo de enfermedades cardiovasculares y enfermedad renal crónica (ERC), consideradas en Colombia las primeras causas de muerte (3).

Según la guía de práctica clínica (GPC) nacional, el objetivo del manejo de la DM2 es lograr el control metabólico a través de modificación de estilos de vida y tratamiento farmacológico, empleando antidiabéticos orales en monoterapia o 
en combinación, principalmente con metformina. A pesar de la efectividad de este tratamiento, persiste un número importante de pacientes que no logra las cifras de control (hemoglobina glucosilada $\left[\mathrm{HbA}_{1 \mathrm{c}}\right]<7 \%$ ) para quienes la terapia farmacológica intensiva o en combinación con otros medicamentos se presenta como una alternativa de manejo retadora durante la toma de decisiones clínicas (5).

Los recientes consensos internacionales proponen no solo adoptar como meta el control de la $\mathrm{HbA}_{1 c}$, sino también que, a través de nuevas herramientas farmacológicas, se favorezcan desenlaces de importancia clínica como el cardiovascular y renal (1).

Los inhibidores de cotransportador de sodio y glucosa tipo 2 (iSGLT2) hacen parte de este grupo de nuevos medicamentos cuyos resultados renales y cardiovasculares sugieren desenlaces favorables. La evidencia disponible incluye poblaciones con factores de riesgo o enfermedad cardiovascular establecida, y presenta algunas limitaciones en el diseño de los estudios, aspectos que dificultan la generalización de los resultados. Ante esta problemática, se planteó como objetivo de la presente revisión recopilar y evaluar la evidencia disponible relacionada con la efectividad y seguridad comparada de los iSGLT2 en pacientes con DM2, en el marco de la definición de un estándar de práctica clínica y posicionamiento terapéutico como alternativa de tratamiento de pacientes con DM2 en instituciones de salud colombianas, en la que se procure el uso racional de estas moléculas, recientemente incluidas en el plan de beneficios en salud (PBS) del país.

\section{Método}

Se realizó una revisión sistemática rápida de la literatura hasta septiembre de 2019, para una pregunta de investigación PICOT definida a priori. La búsqueda de la evidencia se realizó en las bases de datos Medline y Embase a partir del empleo de los términos: "adult, diabetes mellitus type 2, sodium-glucose co-transporter-2 inhibitors, SGLT2 inhibitors, canagliflozin, dapagliflozin, empagliflozin". Además, se consultaron expertos clínicos para rastrear otros artículos. La estrategia de búsqueda por cada base de datos se presenta en el Tabla 1; sin límites por idioma y fecha de publicación.

Los desenlaces primarios de efectividad se categorizaron en cardiovasculares y renales. El desenlace cardiovascular fue el Major Adverse Cardiovascular Event (MACE): muerte por causa cardiovascular, ataque cerebrovascular (ACV) no fatal, infarto agudo de miocardio (IAM) no fatal y hospitalización por insuficiencia cardíaca. El desenlace renal incluyó progresión de enfermedad renal, relación albuminuria-creatinuria, reducción de la tasa estimada de filtración glomerular (eTFG) $<40 \%$ o duplicación de creatinina, necesidad de terapia de reemplazo renal (TRR), trasplante de riñón o eTFG $<15 \mathrm{~mL} / \mathrm{min}$, y muerte por causa renal. Para el desenlace de seguridad, se tuvo en cuenta la hipoglucemia, fractura, infección del tracto genitourinario y eventos adversos asociados con la intervención.

Tabla 1. Estrategia de búsqueda por base de datos consultada

\begin{tabular}{c|l}
\multicolumn{1}{c}{$\#$} & \multicolumn{1}{|c}{ Consulta Embase } \\
\hline S13 & \#5 AND \#12 \\
\hline S12 & \#6 OR \#7 OR \#8 OR \#9 OR \#10 OR \#11 \\
\hline S11 & ertugliflozin \\
\hline S10 & empagliflozin:ab,ti \\
\hline S9 & dapagliflozin:ab,ti \\
\hline S8 & canagliflozin:ab,ti \\
\hline S7 & 'sglt 2':ab,ti \\
\hline S6 & 'sodium glucose cotransporter 2 inhibitor':ab,ti \\
\hline S5 & \#3 AND \#4 \\
\hline S4 & \#1 OR \#2 \\
\hline S3 & adult:ab,ti \\
\hline S2 & 'type 2 diabetes mellitus':ab,ti \\
\hline S1 & 'non insulin dependent diabetes mellitus':ab,ti \\
\hline \# & \\
\hline S7 & S5 AND S6 \\
\hline S6 & S3 OR S4 \\
\hline S5 & S1 AND S2 \\
\hline S4 & $\begin{array}{l}\text { AB canagliflozin OR AB dapagliflozin OR AB } \\
\text { empagliflozin OR AB ertugliflozin }\end{array}$ \\
\hline S3 & $\begin{array}{l}\text { AB SGLT2 OR AB sodium-glucose cotransporter 2 } \\
\text { inhibitors OR AB SGLT2 inhibitors }\end{array}$ \\
\hline S1
\end{tabular}

La selección de artículos y extracción de datos se realizó por un investigador. La selección se realizó a partir del título y resumen; los considerados de potencial elección se revisaron completamente y se verificó que fueran estudios secundarios tipo revisiones sistemáticas de literatura o metaanálisis de ensayos clínicos aleatorizados (ECA), cuya población de estudio fuera de adultos (> 18 años) con diagnóstico de DM2. La intervención de interés correspondió a los iSGLT2 comparado con la terapia estándar. La calidad metodológica fue evaluada con la herramienta A measurement Tool to Assess Systematic Re- 
view (AMSTAR-2) (6) modificada, cuyo resultado también fue un criterio de elegibilidad, de tal manera que las conclusiones se basaran en la mejor y más actualizada evidencia disponible. La síntesis de la evidencia se presenta de manera descriptiva.

\section{Resultados}

Se encontró un total de 224 referencias, de las cuales 28 fueron removidas por duplicidad. La tamización por título y resumen se realizó para 196 referencias, y se excluyeron otras 172 por no cumplir con los criterios de elegibilidad. 24 referencias fueron revisadas a texto completo y se excluyeron 19 por no cumplir con el criterio de comparador, diseño de estudio, reporte incompleto y baja calidad, por lo que finalmente se incluyeron 5 revisiones sistemáticas de la literatura (7-11). El proceso de selección se detalla en la Figura 1. Las exclusiones se detallan en el Tabla 2.

Figura 1. Flujograma de selección de información.

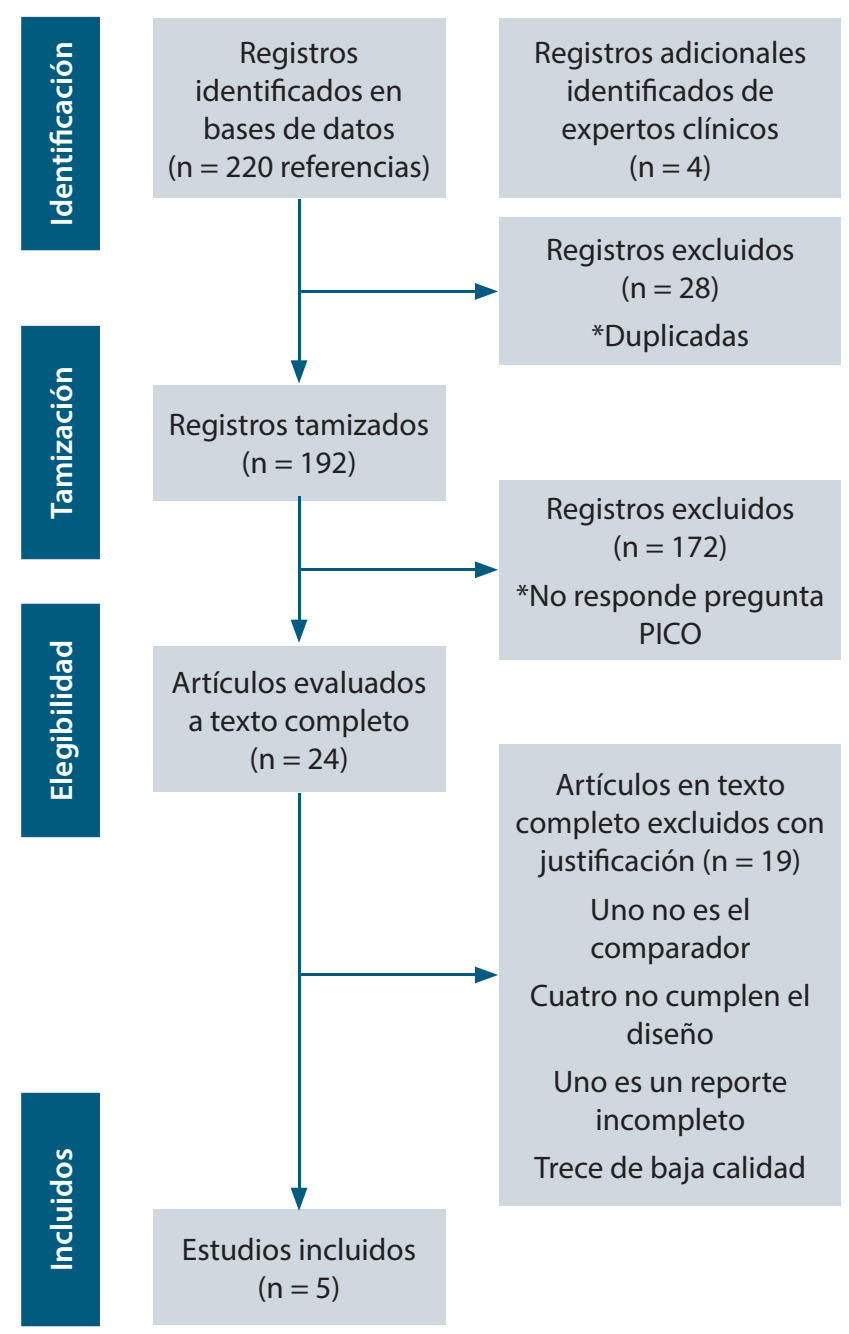

*Motivo de exclusión. PICO: Población, Intervención, Comparador, Desenlaces (Outcome en inglés)

\section{Características de los estudios incluidos}

Se presentan en la Tabla 3. Las revisiones sistemáticas de la literatura incluidas se publicaron entre 2015 y 2019, y obtuvieron una calificación de calidad media y alta según la herramienta AMSTAR-2 modificada. El principal motivo de incumplimiento fue la ausencia de reporte del protocolo preestablecido y la evaluación del sesgo de publicación. Las 5 revisiones sistemáticas de la literatura se basaron en ensayos clínicos aleatorizados que incluyen entre 4 y 48 estudios de este tipo, publicados desde 2011 hasta 2019.

La calidad de los estudios evaluados se realizó con la herramienta de evaluación de riesgo de sesgo de Cochrane (7, $8,10,11)$ y la escala de Jadad modificada (9). Los comparadores fueron: cuidado estándar, agonista del receptor de péptido similar al glucagón tipo 1 (GLP-1), glimepirida, sitagliptina y linagliptina. El desenlace cardiovascular fue evaluado en la revisión de Hussein y colaboradores, 2019 (11); el desenlace renal, por Neuen y colaboradores, 2019 (7), Bae y colaboradores, 2019 (8) y Xu y colaboradores, 2017 (10); y el desenlace de seguridad fue abordado por los estudios de Hussein y colaboradores, 2019 (11) y Liu y colaboradores, 2015 (9). Una de las revisiones sistemáticas de la literatura incluidas integró los resultados de estudios primarios a través de metaanálisis en red o comparaciones indirectas con el fin de comparar los iSGLT2 con análogos del péptido similar al glucagón tipo 1 (aGLP-1) (11); las otras revisiones resultaron en metaanálisis que comparan el cuidado estándar (placebo) u otros antidiabéticos con iSGLT2.

Todas las revisiones sistemáticas de la literatura realizaron análisis por subgrupos, entre los que se encontraban: molécula y duración de la acción (11), tipo de inhibidor, placebo o control activo, uso concomitante de inhibidores RAAS, duración del ensayo clínico, edad basal, duración de DM2, nivel basal de $\mathrm{HbA}_{1 \mathrm{c}}$, ERC (definida como eTFG $<60 \mathrm{~mL} / \mathrm{min} / 1,73 \mathrm{~m}^{2}$ o microalbuminuria o macroalbuminuria), hiperfiltración (definida como eTFG > $125 \mathrm{~mL} / \mathrm{min} \times 1,73 \mathrm{~m}^{2}$ ) (10) y por estudios que no incluyeron sitagliptina (9). Los resultados extraídos de las revisiones sistemáticas de la literatura incluidas se presentan en la Tabla 4.

\section{Desenlace cardiovascular}

Los hallazgos de la revisión de Hussein y colaboradores, presentados en la Tabla 5, se reportaron principalmente para la población con enfermedad cardiovascular establecida. En la comparación de los iSGLT2 con el cuidado estándar, se encontró que la intervención reduce el riesgo de mortalidad cardiovascular en $23 \%$; de mortalidad por todas las causas, en $20 \%$; y de admisión hospitalaria por insuficiencia cardíaca, en $33 \%$. Al comparar el aGLP-1 con los iSGLT2 de manera indirecta a través de un metaanálisis en red, se encontró que los pacientes tratados con iSGLT2 reportaron una menor frecuencia de admisión hospitalaria por insuficiencia cardíaca. 
Tabla 2. Registros excluidos

\begin{tabular}{|c|c|c|}
\hline Autor, año & Título & Motivo de exclusión \\
\hline CADTH, 2019 & Clinical Review Report ERTUGLIFLOZIN (STEGLATRO) & Calidad críticamente baja \\
\hline CADTH, 2019 & Common Drug Review New Combination Product & Reporte incompleto \\
\hline CADTH, 2019 & $\begin{array}{l}\text { Sodium-glucose Co-transporter } 2 \text { Inhibitors for the Treatment of Type } 2 \\
\text { Diabetes: A Review of Clinical Effectiveness, Cost-Effectiveness, and Guidelines }\end{array}$ & Diseño metodológico \\
\hline $\begin{array}{l}\text { Milder et al, } \\
2019\end{array}$ & $\begin{array}{l}\text { Combination Therapy with an SGLT2 Inhibitor as Initial Treatment for Type } 2 \\
\text { Diabetes: A Systematic Review and Meta-Analysis }\end{array}$ & Calidad baja \\
\hline CADTH, 2017 & $\begin{array}{l}\text { Common Drug Review Empagliflozin and Metformin Fixed-Dose Combination } \\
\text { (Synjardy) }\end{array}$ & Calidad críticamente baja \\
\hline CADTH, 2016 & Common Drug Review Dapagliflozin (Forxiga) & Calidad críticamente baja \\
\hline Wu, 2017 & $\begin{array}{l}\text { Effects of sodium-glucose cotransporter- } 2 \text { inhibitors on cardiovascular events, } \\
\text { death, and major safety outcomes in adults with type } 2 \text { diabetes: a systematic } \\
\text { review and meta-analysis }\end{array}$ & Calidad baja \\
\hline $\begin{array}{l}\text { Maruthur et al, } \\
2016\end{array}$ & $\begin{array}{l}\text { Diabetes Medications as Monotherapy or Metformin-Based Combination } \\
\text { Therapy for Type } 2 \text { Diabetes A Systematic Review and Meta-analysis }\end{array}$ & Calidad críticamente baja \\
\hline Xiong et al, 2016 & $\begin{array}{l}\text { Efficacy and safety of canagliflozin in patients with type } 2 \text { diabetes A meta- } \\
\text { analysis of randomized controlled trials }\end{array}$ & No comparador \\
\hline $\begin{array}{l}\text { Zaccardi et al, } \\
2016\end{array}$ & $\begin{array}{l}\text { Efficacy and safety of sodium-glucose co-transporter- } 2 \text { inhibitors in type } 2 \\
\text { diabetes mellitus: systematic review and network meta-analysis }\end{array}$ & Calidad baja \\
\hline CADTH, 2019 & Common Drug Review Empagliflozin (Jardiance) & Calidad baja \\
\hline $\begin{array}{l}\text { Mearns et al, } \\
2015\end{array}$ & $\begin{array}{l}\text { Efficacy and safety of antihyperglycaemic drug regimens added to metformin } \\
\text { and sulphonylurea therapy in Type } 2 \text { diabetes: a network meta-analysis }\end{array}$ & Calidad críticamente baja \\
\hline $\begin{array}{l}\text { Rosenstock et al, } \\
2015\end{array}$ & $\begin{array}{l}\text { Dual Add-on Therapy in Type 2Diabetes Poorly Controlled with Metformin } \\
\text { Monotherapy: A Randomized Double-Blind Trial of Saxagliptin Plus } \\
\text { Dapagliflozin Addition Versus Single Addition of Saxagliptin or Dapagliflozin to } \\
\text { Metformin }\end{array}$ & Diseño metodológico \\
\hline $\begin{array}{l}\text { Saeed y } \\
\text { Narendran, } 2014\end{array}$ & Dapagliflozin for the treatment of type 2 diabetes: a review of the literature & Revisión narrativa \\
\hline Scott, 2014 & Empagliflozin: A Review of Its Use in Patients with Type 2 Diabetes Mellitus & Revisión narrativa \\
\hline Sun et al, 2014 & $\begin{array}{l}\text { The efficacy of dapagliflozin combinedwith hypoglycaemic drugs in } \\
\text { treatingtype } 2 \text { diabetes mellitus: meta-analysis of randomised controlled trials }\end{array}$ & Calidad baja \\
\hline $\begin{array}{l}\text { Vasilacou et al, } \\
2013\end{array}$ & $\begin{array}{l}\text { Sodium-Glucose Cotransporter } 2 \text { Inhibitors for Type } 2 \text { Diabetes A Systematic } \\
\text { Review and Meta-analysis }\end{array}$ & Calidad baja \\
\hline $\begin{array}{l}\text { Zelniker et al, } \\
2019\end{array}$ & $\begin{array}{l}\text { Comparison of the Effects of Glucagon-Like Peptide Receptor Agonists and } \\
\text { Sodium-Glucose Cotransporter } 2 \text { Inhibitors for Prevention of Major Adverse } \\
\text { Cardiovascular and Renal Outcomes in Type } 2 \text { Diabetes Mellitus Systematic } \\
\text { Review and Meta-Analysis of Cardiovascular Outcomes Trials }\end{array}$ & Calidad baja \\
\hline $\begin{array}{l}\text { Zelniker et al, } \\
2018\end{array}$ & $\begin{array}{l}\text { SGLT2 inhibitors for primary and secondary prevention of cardiovascular and } \\
\text { renal outcomes in type } 2 \text { diabetes: a systematic review and meta-analysis of } \\
\text { cardiovascular outcome trials }\end{array}$ & Calidad baja \\
\hline
\end{tabular}


Tabla 3. Características de las revisiones sistemáticas de la literatura incluidas

\begin{tabular}{|c|c|c|c|c|c|c|c|c|}
\hline Autor & $\begin{array}{l}\text { Diseño de } \\
\text { estudios } \\
\text { primarios, } \\
\mathbf{n}\end{array}$ & \multicolumn{2}{|c|}{ Estudios primarios incluidos } & $\begin{array}{l}\text { Criterios de } \\
\text { elegibilidad }\end{array}$ & Intervención & Comparador & Desenlaces & $\begin{array}{c}\text { Tiempo } \\
\text { de segui- } \\
\text { miento }\end{array}$ \\
\hline $\begin{array}{l}\text { Hussein, } \\
2019\end{array}$ & $\begin{array}{l}8 \mathrm{ECA}, \\
60082\end{array}$ & \multicolumn{2}{|c|}{$\begin{array}{l}\text { Zinman B et al, } 2015 \text { (EMPA-REG } \\
\text { OUTCOME); Neal B et al, } 2017 \\
\text { (CANVAS); Pfeffer MA et al, } 2015 \\
\text { (ELIXA); Marso SP et al } 2016 \text { (LEADER); } \\
\text { Marso SP et al, } 2016 \text { (SUSTAIN-6); } \\
\text { Holman RR et al, } 2017 \text { (EXSCEL); } \\
\text { Hernández AF et al, } 2018 \text { (HARMONY) }\end{array}$} & $\begin{array}{l}\text { Inclusión, ECA, } \\
\text { adultos con DM2, } \\
\text { objetivo: seguridad y } \\
\text { eficacia cardiovascular } \\
\text { de SGLT2 o aGLP-1 }\end{array}$ & $\begin{array}{l}\text { SGLT2 o aGLP-1 } \\
\text { Empagliflozina } \\
\text { Canagliflozina } \\
\text { Dapagliflozina }\end{array}$ & $\begin{array}{l}\text { Placebo, SGLT2 } \\
\text { o aGLP-1 }\end{array}$ & $\begin{array}{l}\text { Eficacia: } \\
\text { *MACE } 3 \text { puntos, } \\
\text { ACV no fatal, } \\
\text { IAM no fatal, } \\
\text { mortalidad } \\
\text { cardiovascular } \\
\text { *Todas las causas } \\
\text { de mortalidad } \\
\text { *Readmisión } \\
\text { hospitalaria para } \\
\text { insuficiencia } \\
\text { cardíaca } \\
\text { Seguridad: } \\
\text { eventos de } \\
\text { hipoglucemia, } \\
\text { fractura de hueso, } \\
\text { amputación, } \\
\text { infección del } \\
\text { tracto urinario, } \\
\text { pancreatitis, } \\
\text { cetoacidosis } \\
\text { diabética }\end{array}$ & $\begin{array}{l}83,3 \text { a } \\
296,4 \\
\text { semanas }\end{array}$ \\
\hline $\begin{array}{l}\text { Neuen, } \\
2019\end{array}$ & $\begin{array}{l}4 \mathrm{ECA} \\
38723\end{array}$ & \multicolumn{2}{|c|}{$\begin{array}{l}\text { Zinman B et al, } 2015 \text { (EMPA-REG } \\
\text { OUTCOME); Neal B et al, } 2017 \\
\text { (CANVAS); DECLARE TIMI 58- } \\
\text { CREDENCE }\end{array}$} & $\begin{array}{l}\text { Inclusión, ECA, } \\
\text { adultos con DM2 }\end{array}$ & $\begin{array}{l}\text { Empagliflozina: } \\
10 \text { y } 25 \\
\text { Canagliflozina: } \\
100 \text { y } 300 \\
\text { Dapagliflozina: } \\
10\end{array}$ & $\begin{array}{l}\text { Placebo, control } \\
\text { activo }\end{array}$ & $\begin{array}{l}\text { Compuesto de } \\
\text { diálisis crónica, } \\
\text { trasplante de } \\
\text { riñón o muerte } \\
\text { debido a } \\
\text { enfermedad del } \\
\text { riñón }\end{array}$ & $\begin{array}{l}135,2 \text { a } \\
218,4 \\
\text { semanas }\end{array}$ \\
\hline $\begin{array}{l}\text { Bae, } \\
2019\end{array}$ & $\begin{array}{l}48 \mathrm{ECA} \\
58165\end{array}$ & $\begin{array}{l}\text { Bailey, 81; } \\
\text { Barnett, 35; } \\
\text { Bolinder, 46; } \\
\text { Cefalu, 39; } \\
\text { Cherney, 7b; } \\
\text { Forst, 49; Häring, } \\
\text { 32; Häring, 33; } \\
\text { Heerspink, 59; } \\
\text { Inagaki, 82; } \\
\text { Januzzi, 83; Ji, } \\
84 ; \text { Ji, 43; Kaku, } \\
\text { 85; Kashiwagi, } \\
\text { 63; Kohan, 15; } \\
\text { Kovacs, 34; } \\
\text { Kovacs, 61; } \\
\text { Kosiborod, 30 } ; \\
\text { Leiter,38; Lu, 52; } \\
\text { Neal, 9; Perkovic, } \\
\text { 20; Perkovic, } \\
\text { 22c; Pollock, 21; } \\
\text { Rodbard, } 51\end{array}$ & $\begin{array}{l}\text { Rosenstock, } \\
\text { 62; Søfteland, } \\
\text { 53; Strojek, 86; } \\
\text { Tikkanen, 54; } \\
\text { Wanner, 6; Weber, } \\
\text { 40; Wilding, 48; } \\
\text { Wilding, 65; Yale, } \\
\text { 60; Cefalu, 50; } \\
\text { DeFronzo, 44; } \\
\text { Frías, 55; Hadjadj, } \\
\text { 57; Heerspink, 8; } \\
\text { Leiter, 41; Lewin, } \\
\text { 56; Nauck, 47; } \\
\text { Ridderstrăle, } \\
\text { 45; Roden, 31; } \\
\text { Rosenstock, 58; } \\
\text { Schernthaner, 42; } \\
\text { Stenlöf, 64 }\end{array}$ & $\begin{array}{l}\text { ECA, comparaban los } \\
\text { iSGLT2 con placebo } \\
\text { u otros fármacos } \\
\text { antidiabéticos } \\
\geq 12 \text { semanas de } \\
\text { duración del estudio } \\
\text { Pacientes con } \\
\text { diabetes tipo } 2\end{array}$ & $\begin{array}{l}\text { Empagliflozina, } \\
\text { canagliflozina, } \\
\text { dapagliflozina }\end{array}$ & $\begin{array}{l}\text { Placebo, } \\
\text { antidiabéticos: } \\
\text { glimepirida, } \\
\text { linagliptina, } \\
\text { sitagliptina, } \\
\text { metformina }\end{array}$ & $\begin{array}{l}\text { Relación } \\
\text { albuminuria- } \\
\text { creatinuria (UACR) } \\
\text { TFG } \\
\text { Microalbuminuria } \\
\text { (UACR > } 30 \mathrm{mg} / \mathrm{g} \text { ) } \\
\text { Macroalbuminuria } \\
\text { incidentes (UACR } \\
>300 \mathrm{mg} / \mathrm{g} \text { ) } \\
\text { Duplicación de la } \\
\text { creatinina sérica } \\
\text { Insuficiencia renal } \\
\text { Enfermedad renal } \\
\text { en estadio final } \\
\text { Terapia de } \\
\text { reemplazo } \\
\text { renal, diálisis o } \\
\text { trasplante de } \\
\text { riñón }\end{array}$ & $\begin{array}{l}12 \text { a } 296 \\
\text { semanas }\end{array}$ \\
\hline
\end{tabular}

No hubo resultados concluyentes respecto al MACE compuesto de 3 puntos, definido previamente en la metodología y tampoco en los desenlaces medidos de forma independiente (ACV, IAM, mortalidad cardiovascular y mortalidad por todas las causas).

\section{Desenlace renal}

Fue abordado por 3 de las 5 revisiones $(7,8,10)$; los hallazgos se resumen en la Tabla 6. La eTFG fue evaluada por Xu y colaboradores (10), y Bae y colaboradores (8). Ambos estudios coinciden en que no hay diferencias en este desenlace al 
Tabla 3. Características de las revisiones sistemáticas de la literatura incluidas (continuación)

\begin{tabular}{|c|c|c|c|c|c|c|c|c|}
\hline Autor & $\begin{array}{c}\text { Diseño de } \\
\text { estudios } \\
\text { primarios, } \\
\mathbf{n}\end{array}$ & \multicolumn{2}{|c|}{ Estudios primarios incluidos } & $\begin{array}{l}\text { Criterios de } \\
\text { elegibilidad }\end{array}$ & Intervención & Comparador & Desenlaces & $\begin{array}{c}\text { Tiempo } \\
\text { de segui- } \\
\text { miento }\end{array}$ \\
\hline$X u, 2017$ & $\begin{array}{l}47 \text { ECA, } \\
22843\end{array}$ & $\begin{array}{l}\text { Baile et al, } 2015 \\
\text { Barnett et al, } \\
2014 \\
\text { Bode et al, } 2013 \\
\text { Bolinder et al, } \\
2012 \\
\text { Cefalu et al, } 2013 \\
\text { DeFronzo et al, } \\
2015 \\
\text { Fonseca et al, } \\
2013 \\
\text { Forst et al, } 2014 \\
\text { Haring et al, } 2014 \\
\text { Haring et al, } 2013 \\
\text { Inagaki et al, } \\
2014 \\
\text { Ji et al, } 2015 \\
\text { Ji et al, } 2014 \\
\text { Kadowaki et al, } \\
2014 \\
\text { Kashiwagi et al, } \\
2015^{\text {a }} \\
\text { Kashiwagi et al, } \\
2015^{b} \\
\text { Kashiwagi et al, } \\
2015^{c} \\
\text { Kashiwagi et al, } \\
2015^{\mathrm{d}} \\
\text { Kohan et al, } 2014 \\
\text { Kovacs et al, } \\
2014 \\
\text { Lambers } \\
\text { Heerspink et al, } \\
2013 \\
\text { Lavalle-Gonzalez } \\
\text { et al, } 2013\end{array}$ & $\begin{array}{l}\text { Lewin et al, } 2015 \\
\text { Lu et al, } 2016 \\
\text { Nauck et al, } 2011 \\
\text { Nishimura et al, } \\
2015 \\
\text { Qiu, Capuano y } \\
\text { Meininger, } 2014 \\
\text { Ridderstrale et al, } \\
2014 \\
\text { Rodbard et al, } 2016 \\
\text { Roden et al, } 2013 \\
\text { Rosenstock et al, } \\
2016 \\
\text { Rosenstock et al, } \\
2014 \\
\text { Rosenstock et al, } \\
2015 \\
\text { Ross et al, } 2015 \\
\text { Schernthaner et al, } \\
2013 \\
\text { SchummDraeger et } \\
\text { al, } 2015 \\
\text { Sha et al, } 2014 \\
\text { Strojek et al, } 2011 \\
\text { Tikkanen et al, } 2015 \\
\text { Wanner et al, } 2016 \\
\text { Weber et al, } 2016 \\
\text { Wilding et al, } 2013^{\text {a }} \\
\text { Wilding et al, } 2013^{\text {b }} \\
\text { Wilding et al, } 2009 \\
\text { Wilding et al, } 2012 \\
\text { Yale et al, } 2013\end{array}$ & $\begin{array}{l}\text { Inclusión: } \\
\text { Adultos con DM2 } \\
\text { Compara inhibidores } \\
\text { SGLT2 con placebo u } \\
\text { otro antidiabético } \\
\text { Reporte de cambios } \\
\text { en la TFG y relación } \\
\text { albúmina/creatinina } \\
\text { Publicación en inglés } \\
\text { Exclusión: } \\
\text { Múltiples } \\
\text { publicaciones del } \\
\text { mismo estudio } \\
\text { (se incluye solo la } \\
\text { primera) }\end{array}$ & SGLT2 & $\begin{array}{l}\text { Placebo } \\
\text { antidiabético }\end{array}$ & $\begin{array}{l}\text { Cambios en la } \\
\text { TFG y relación } \\
\text { albúmina/ } \\
\text { creatinina }\end{array}$ & $\begin{array}{l}12 \text { a } 156 \\
\text { semanas }\end{array}$ \\
\hline $\begin{array}{l}\text { Liu, } \\
2015\end{array}$ & $14 \mathrm{ECA}$ & $\begin{array}{l}\text { Bailey et al, } 2013 \\
\text { Barnett et al, } 2014 \\
\text { Bode et al, } 2015 \\
\text { Bolinder et al, } 201 \\
\text { Cefalu et al, } 2013 \\
\text { Lavalle Gonzalez } \\
\text { Leiter et al, 2014 } \\
\text { Nauck et al, 2011, } \\
\text { Ridderstrale et al, } \\
\text { Rosenstock et al, } \\
\text { Schernthaner et a } \\
\text { Wilding, Woo, Roh } \\
\text { Parikh, 2014 } \\
\text { Wilding et al, } 201\end{array}$ & $\begin{array}{l}4 \\
4 \\
\text { t al, } 2013 \\
2014 \\
2014 \\
014 \\
\text {, } 2013 \\
\text { wedder, Sugg y }\end{array}$ & $\begin{array}{l}\text { Inclusión: ECA de } \\
\text { eficacia y seguridad } \\
\text { de los iSGLT2 } \\
\text { Comparación con } \\
\text { placebo o antidiabéti- } \\
\text { cos orales } \\
\text { DM2 inadecuadamen- } \\
\text { te controlada } \\
\text { Al menos una medida } \\
\text { de resultado de efica- } \\
\text { cia y seguridad } \\
\text { Mayores de } 18 \text { años } \\
\text { ECA de al menos } 52 \\
\text { semanas } \\
\text { Exclusión: ECA infor- } \\
\text { mación inadecuada } \\
\text { de resultados de } \\
\text { eficacia y seguridad } \\
\text { ECA sin grupo control } \\
\text { ECA duración menor a } \\
52 \text { semanas } \\
\text { Ensayos con parti- } \\
\text { cipantes que tenían } \\
\text { un aclaramiento de } \\
\text { creatinina calculado o } \\
\text { TFG estimada inferior } \\
\text { a } 50 \text { mL/min/1,73 m² }\end{array}$ & $\begin{array}{l}\text { SGLT2: } \\
\text { empagliflozina, } \\
\text { canagliflozina, } \\
\text { dapagliflozina }\end{array}$ & $\begin{array}{l}\text { Placebo } \\
\text { Antidiabéticos } \\
\text { orales: glipizida, } \\
\text { glimepirida }\end{array}$ & $\begin{array}{l}\text { Eficacia: control } \\
\text { glucémico, peso } \\
\text { corporal, presión } \\
\text { arterial } \\
\text { Seguridad: } \\
\text { hipoglucemia, } \\
\text { infecciones } \\
\text { urinarias y } \\
\text { genitales }\end{array}$ & $\begin{array}{l}52 \text { a } 104 \\
\text { semanas }\end{array}$ \\
\hline
\end{tabular}

ECA: ensayo clínico aleatorizado. 
Tabla 4. Resultados de las revisiones sistemáticas de la literatura incluidas

\begin{tabular}{|c|c|c|c|c|}
\hline Autor & $\begin{array}{c}\text { Diseño } \\
\text { estudios } \\
\text { primarios, n }\end{array}$ & $\begin{array}{c}\text { Meta- } \\
\text { análisis }\end{array}$ & $\begin{array}{l}\text { Análisis por } \\
\text { subgrupos }\end{array}$ & Resultados \\
\hline $\begin{array}{l}\text { Hussein, } \\
2019\end{array}$ & $\begin{array}{l}8 \mathrm{ECA}, \\
60082\end{array}$ & Sí & $\begin{array}{l}\text { Duración de } \\
\text { acción: } \\
\text { Corta } \\
\text { Larga } \\
\text { Molécula: } \\
\text { Basada en } \\
\text { exendina } \\
\text { Sin exendina }\end{array}$ & $\begin{array}{l}\text { iSGLT2 frente a aGLP-1: } \\
\text { Eficacia: } \\
\text { MACE: HR: } 1,02 \text { (IC } 95 \%: 0,83 \text { a 1,23) } \\
\text { ACV no fatal: HR: } 0,86 \text { (IC } 95 \%: 0,55 \text { a 1,30) } \\
\text { IAM no fatal: HR: 1,08 (0,82 a 1,37) } \\
\text { Mortalidad cardiovascular: HR: 1,18 (0,86 a 1,59) } \\
\text { Mortalidad por todas las causas: HR: } 1,13(0,92 \text { a 1,39) } \\
\text { Ingreso hospitalario por insuficiencia cardíaca: HR: 0,71 (IC } 95 \% 0,53 \text { a 0,93) } \\
\text { Seguridad: } \\
\text { Hipoglucemia: OR: } 0,98 \text { (0,63 a 1,53) } \\
\text { Fractura ósea: OR: } 1,24(0,32 \text { a 5,12) } \\
\text { Amputación: OR: } 0,69(0,09 \text { a 9,35) } \\
\text { Pancreatitis: OR: } 1,22 \text { (0,20 a 6,70) } \\
\text { Infección del tracto urinario: OR: } 0,71(0,10 \text { a 5,57) } \\
\text { Cetoacidosis diabética: OR: } 0,03(0,00 \text { a } 685,60)\end{array}$ \\
\hline $\begin{array}{l}\text { Neuen, } \\
2019\end{array}$ & $\begin{array}{l}4 \mathrm{ECA} \\
38723\end{array}$ & Sí & $\begin{array}{l}\text { Función renal } \\
\text { basal } \\
\text { Excreción } \\
\text { urinaria de } \\
\text { albúmina } \\
\text { Uso basal de } \\
\text { bloqueantes } \\
\text { del RAS }\end{array}$ & 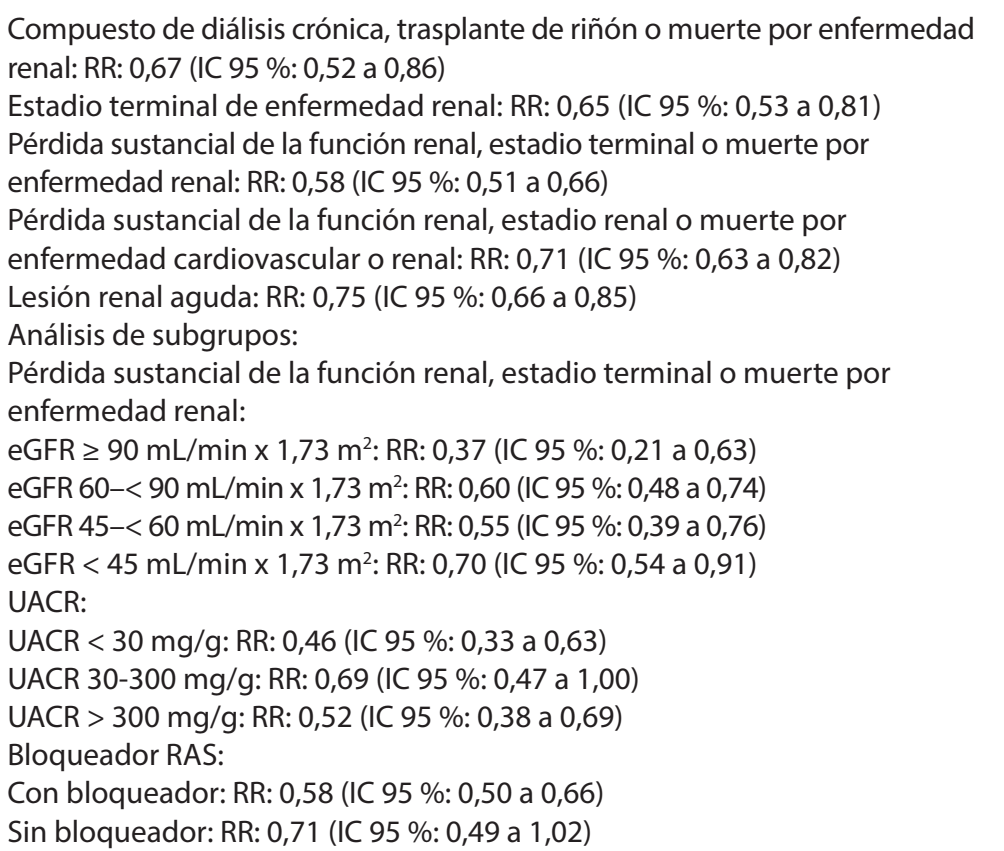 \\
\hline $\begin{array}{l}\text { Bae, } \\
2019\end{array}$ & $\begin{array}{l}48 \text { ECA, } 58 \\
165\end{array}$ & Sí & $\begin{array}{l}\text { TFG basal } \\
\text { y TFG de } \\
\text { referencia } \\
\text { Relación } \\
\text { albuminuria- } \\
\text { creatinuria } \\
\text { Duración del } \\
\text { estudio }\end{array}$ & 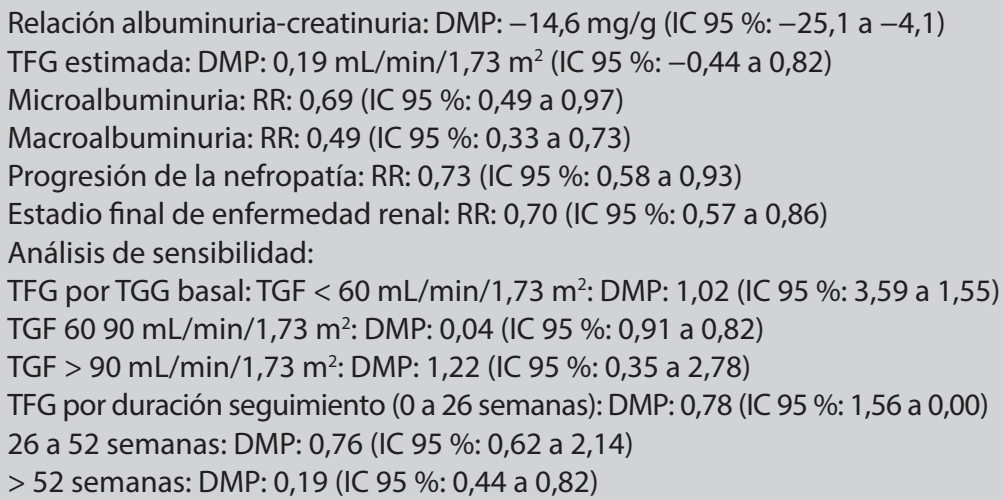 \\
\hline
\end{tabular}


Tabla 4. Resultados de las revisiones sistemáticas de la literatura incluidas (continuación)

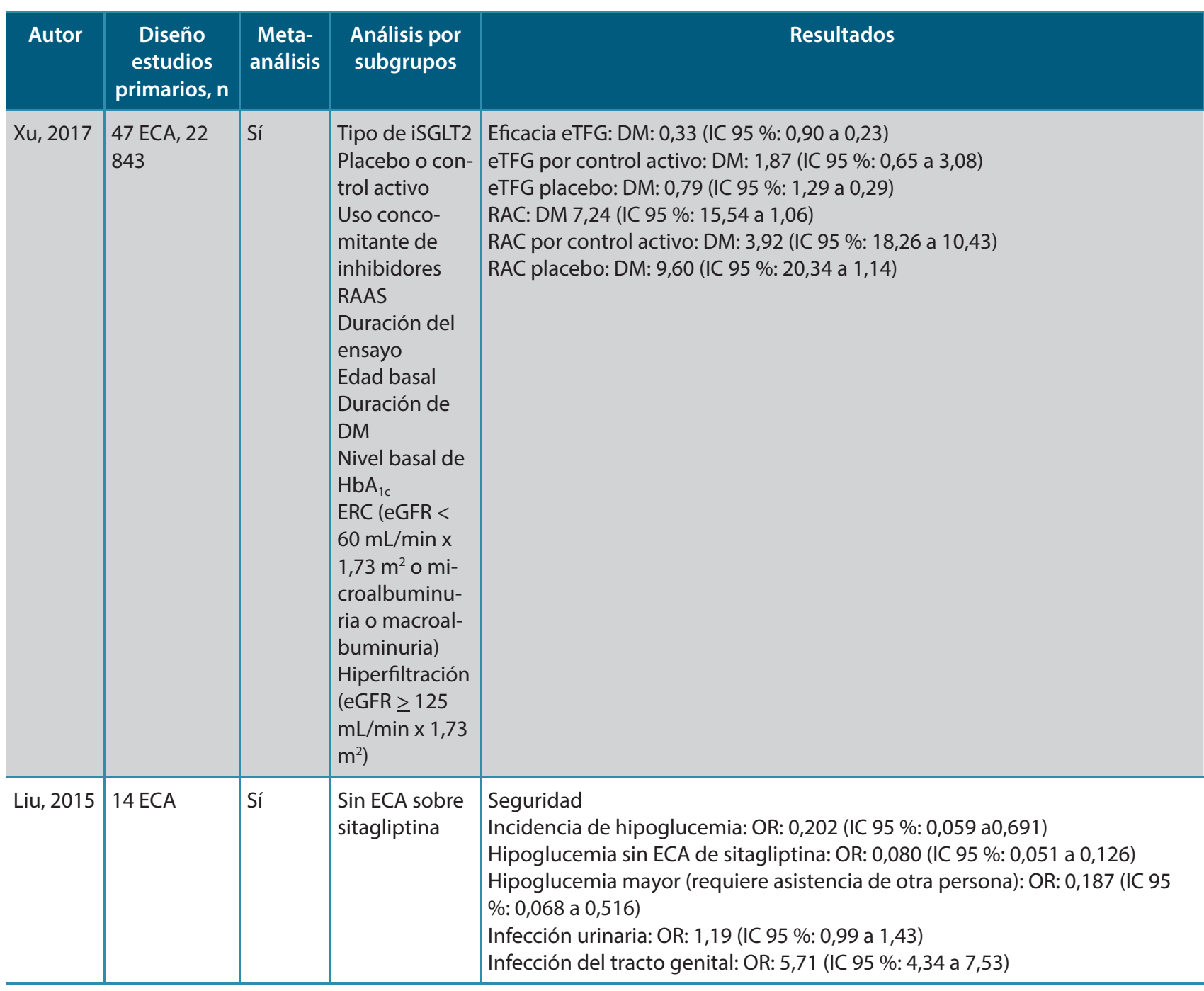

DM: diferencia de medias; DMP: Diferencia de media ponderada, IC: intervalo de confianza; HR: Hazard ratio; OR: Odds ratio; RAAS: sistema renina-angiotensinaaldosterona; RAC: Relación albumina-creatinina; RAS: sistema renina-angiotensina; RR: riesgo relativo.

comparar los iSGLT2 con comparadores activos (glimepirida, glipizida, sitagliptina, linagliptina) o el cuidado estándar, aunque existe una heterogeneidad considerable entre los estudios primarios incluidos. En los análisis por subgrupos realizados por Xu y colaboradores respecto a la duración de los estudios, se encontró un descenso más lento en el grupo que recibió iSGLT2 respecto al comparador en tiempos superiores de 52 semanas; este último fue en promedio de 1,73 $\mathrm{m}^{2}$ (IC $95 \%$ : 0,86 a 3,16), mientras que en estudios menores de 26 semanas la tendencia es a favor del comparador. En el grupo de pacientes con DM2 de más de 10 años de duración hubo una reducción más rápida en comparación con el control, que fue en promedio de 1,23 mL/min/1,73 $\mathrm{m}^{2}$ (10). En los hallazgos de Bae y colaboradores se sugiere que la disminución de la eTFG fue más lenta en pacientes con una eTFG basal más alta $(p=0,116)$ y una mayor duración del seguimiento $(p=0,038)$, resultado semejante al reportado por Xu y colaboradores.

Xu y colaboradores (10), y Bae y colaboradores (8) también estudiaron la relación albuminuria-creatinuria, pero los hallazgos no son consistentes entre estos estudios; mientras que Xu y colaboradores (10), con un tiempo de seguimiento entre 12 y 296 semanas, no encontraron diferencias significativas entre los iSGLT2 y el comparador (glimepirida, linagliptina, glipizida, sitagliptina y cuidado estándar [placebo]). Bae 
y colaboradores (8), en seguimientos entre 4 y 156 semanas, encontraron una reducción promedio de 14,64 mg/g en la relación albuminuria-creatinuria a favor de los iSGLT2 cuando se comparó contra el cuidado estándar u otros antidiabéticos (glimepirida, glipizida y linagliptina) y, además, reportaron resultados para microalbuminuria, macroalbuminuria, em- peoramiento de nefropatía y enfermedad renal en estadio final. Sus hallazgos muestran una reducción del riesgo de todos estos desenlaces al comparar los iSGLT2 con un grupo control. Los iSGLT2 redujeron el $31 \%$ de microalbuminuria, $51 \%$ de macroalbuminuria, $27 \%$ de progresión de la nefropatía y $30 \%$ de la enfermedad renal en estadio final.

Tabla 5. Resultados de las revisiones sistemáticas de la literatura incluidas respecto al desenlace cardiovascular

\begin{tabular}{l|c|c}
\multicolumn{1}{c|}{ Desenlace cardiovascular } & Hussein y colaboradores, 2019 (aGLP-1) & Hussein y colaboradores, 2019 (cuidado estándar) \\
\hline MACE & HR: 1,02 (IC $95 \%: 0,83$ a 1,23) & 0,86 (IC 95 \%: 0,74 a 1,01) \\
\hline ACV no fatal & HR: 0,86 (IC $95 \%: 0,55$ a 1,30) & 1,03 (IC 95 \%: 0,74 a 1,43) \\
\hline IAM no fatal & HR: $1,08(0,82$ a 1,37) & 0,87 (IC 95 \%: 0,72 a 1,07) \\
\hline Mortalidad cardiovascular & HR: $1,18(0,86$ a 1,59) & 0,77 (IC 95 \%: 0,61 a 0,99) \\
\hline Mortalidad todas las causas & HR: $1,13(0,92$ a 1,39) & 0,80 (IC 95 \%: 0,68 a 0,95) \\
\hline $\begin{array}{l}\text { Ingreso hospitalario por } \\
\text { insuficiencia cardíaca }\end{array}$ & HR: 0,71 (IC $95 \%: 0,53$ a 0,93) & 0,67 (IC $95 \%: 0,53$ a 0,85) \\
\hline
\end{tabular}

Tabla 6. Resultados de las revisiones sistemáticas de la literatura incluidas respecto al desenlace renal

\begin{tabular}{|c|c|c|c|}
\hline Desenlace renal & $\begin{array}{c}\text { Neuen y } \\
\text { colaboradores, } 2019\end{array}$ & $\begin{array}{l}\text { Bae y colaboradores, } \\
\qquad 2019\end{array}$ & $\begin{array}{l}\text { Xu y colaboradores, } \\
2017\end{array}$ \\
\hline $\begin{array}{l}\text { Compuesto de diálisis crónica, trasplante de riñón o } \\
\text { muerte por enfermedad renal }\end{array}$ & $\begin{array}{c}\text { RR: } 0,67 \\
\text { (IC } 95 \%: 0,52 \text { a } 0,86)\end{array}$ & & \\
\hline Enfermedad renal en estadio final & $\begin{array}{c}\text { RR: 0,65 (IC } 95 \%: 0,53 \\
\text { a } 0,81)\end{array}$ & $\begin{array}{l}\text { RR: } 0,70 \text { (IC } 95 \%: 0,57 \\
\text { a } 0,86)\end{array}$ & \\
\hline $\begin{array}{l}\text { Pérdida sustancial de la función renal, estadio final o } \\
\text { muerte por enfermedad renal }\end{array}$ & $\begin{array}{c}\text { RR: 0,58 (IC } 95 \%: 0,51 \\
\text { a } 0,66)\end{array}$ & & \\
\hline $\begin{array}{l}\text { Pérdida sustancial de la función renal, estadio final o } \\
\text { muerte por enfermedad cardiovascular o renal }\end{array}$ & $\begin{array}{c}\text { RR: 0,71 (IC } 95 \%: 0,63 \\
\text { a } 0,82)\end{array}$ & & \\
\hline Lesión renal aguda & $\begin{array}{l}\text { RR: } 0,75 \text { (IC } 95 \%: 0,66 \\
\text { a } 0,85)\end{array}$ & & \\
\hline Relación albuminuria-creatinuria & & $\begin{array}{l}\text { DMP: }-14,6 \text { (IC } 95 \%: \\
\quad-25,1 \mathrm{a}-4,1)\end{array}$ & $\begin{array}{l}\text { DM: 7,24 (IC } 95 \%: \\
\quad 15,54 \text { a } 1,06)\end{array}$ \\
\hline eTFG & & $\begin{array}{l}\text { DMP: } 0,19 \text { (IC } 95 \% \text { : } \\
\quad-0,44 \text { a } 0,82)\end{array}$ & $\begin{array}{l}\text { DM: } 0,33 \text { (IC } 95 \%: \\
\quad 0,90 \text { a } 0,23)\end{array}$ \\
\hline Microalbuminuria & & $\begin{array}{c}\text { RR: 0,69 (IC } 95 \%: 0,49 \\
\text { a } 0,97)\end{array}$ & \\
\hline Macroalbuminuria & & $\begin{array}{c}\text { RR: } 0,49 \text { (IC } 95 \%: 0,33 \\
\text { a } 0,73)\end{array}$ & \\
\hline Progresión de la nefropatía & & $\begin{array}{c}\text { RR: 0,73 (IC } 95 \%: 0,58 \\
\text { a } 0,93)\end{array}$ & \\
\hline
\end{tabular}


Neuen y colaboradores evaluaron el desenlace renal compuesto (diálisis, trasplante o muerte por enfermedad renal) y encontraron que los iSGLT2 reducen el riesgo para este desenlace en el $33 \%$, la muerte por causa renal en el $42 \%$ y la lesión renal aguda en el $25 \%$ respecto al comparador (cuidado estándar o antidiabéticos). En el análisis por subgrupos realizados por este autor, se mantienen los resultados a favor de la intervención para el desenlace de pérdida de función renal, enfermedad renal en estadio final o muerte por enfermedad renal, excepto para los subgrupos de relación albuminuria-creatinuria entre 30 y 300 mg/g y no uso de bloqueante del RAS (7).

\section{Desenlace de seguridad}

Este resultado se reportó en las revisiones sistemáticas de la literatura de Hussein y colaboradores (11), y Liu y colaboradores (9). El resumen de los hallazgos se presenta en la Tabla 7. La hipoglucemia fue un desenlace incluido en ambas revisiones sistemáticas de la literatura, pero los resultados no son consistentes. Mientras que en la revisión de Liu y colaboradores se encontró un aumento en el riesgo de hipoglucemia, alrededor del $20 \%$ al comparar los iSGLT2 con el cuidado estándar, y una reducción del $80 \%$ al comparar los iSGLT2 con antidiabéticos orales. Respecto a la hipoglucemia grave, los iSGLT2 en comparación con los antidiabéticos orales redujeron el riesgo de presentación, alrededor del $81 \%$; sin embargo, al comparar los iSGLT2 con el cuidado estándar no se reportaron diferencias. Contrariamente, en la revisión de Hussein y colaboradores no hubo diferencias entre los iSGLT2 y los comparadores para el desenlace de hipoglucemia.

Además, en la revisión de Hussein y colaboradores se incluyó la fractura ósea, amputación, pancreatitis y cetoacidosis diabética, para los cuales tampoco se encontraron diferencias en la comparación de los iSGLT2 con el cuidado estándar o los aGLP-1 (11).

Respecto a las infecciones de tracto genitourinario, tanto Liu y colaboradores como Hussein y colaboradores analizaron este desenlace, aunque obtuvieron resultados inconsistentes entre ellos. Liu y colaboradores, en seguimientos entre 52 y 104 semanas, encontraron que en el grupo de pacientes tratados con iSGLT2 se reportó una mayor frecuencia de infecciones urinarias (OR: 1,477; IC 95 \%: 1,172 a 1,861) e infecciones del tracto genital (OR: 4,196; IC $95 \%$ : 2,332 a 7,55) con respecto al cuidado estándar. En el análisis comparativo con antidiabéticos orales, hubo mayor presentación de infecciones del tracto genital (OR: 5,715; IC 95 \%: 4,339 a 7,528) en el grupo de iSGLT2 (11); mientras que Hussein y colaboradores, con seguimientos entre 83 y 296 semanas, no encontraron diferencias para este desenlace.

\section{Conclusiones}

La DM2 es una condición crónica objetivo de la agenda de salud pública mundial y nacional, para la cual se proyecta un
Tabla 7. Resultados de revisiones sistemáticas de la literatura incluidas respecto a desenlace de seguridad

\begin{tabular}{|c|c|c|}
\hline $\begin{array}{l}\text { Desenlace de } \\
\text { seguridad }\end{array}$ & $\begin{array}{c}\text { Hussein y } \\
\text { colaboradores, } \\
2019 \text { (aGLP-1) }\end{array}$ & $\begin{array}{c}\text { Liu y } \\
\text { colaboradores, } \\
2015\end{array}$ \\
\hline Hipoglucemia & $\begin{array}{c}\text { OR: 0,98 (IC } 95 \%: \\
\quad 0,63 \text { a 1,53) }\end{array}$ & $\begin{array}{c}\text { OR: 0,202 (IC } 95 \% \text { : } \\
\text { 0,059 a 0,691) }\end{array}$ \\
\hline $\begin{array}{l}\text { Hipoglucemia } \\
\text { grave }\end{array}$ & & $\begin{array}{c}\text { OR: 0,187 (IC } 95 \% \text { : } \\
\quad 0,068 \text { a } 0,516)\end{array}$ \\
\hline Fractura ósea & $\begin{array}{l}\text { OR: 1,24 (IC } 95 \%: \\
\quad 0,32 \text { a } 5,12)\end{array}$ & \\
\hline Amputación & $\begin{array}{c}\text { OR: 0,69 (IC } 95 \%: \\
\quad 0,09 \text { a } 9,35)\end{array}$ & \\
\hline Pancreatitis & $\begin{array}{c}\text { OR: 1,22 (IC } 95 \%: \\
0,20 \text { a } 6,70)\end{array}$ & \\
\hline $\begin{array}{l}\text { Infección del } \\
\text { tracto urinario }\end{array}$ & $\begin{array}{l}\text { OR: 0,71 (IC } 95 \% \text { : } \\
\quad 0,10 \text { a } 5,57)\end{array}$ & $\begin{array}{c}\text { OR: } 1,19 \text { (IC } 95 \%: \\
0,99 \text { a } 1,43)\end{array}$ \\
\hline $\begin{array}{l}\text { Infección del } \\
\text { tracto genital }\end{array}$ & & $\begin{array}{c}\text { OR: } 5,71 \text { (IC } 95 \%: \\
4,34 \text { a } 7,53)\end{array}$ \\
\hline $\begin{array}{l}\text { Cetoacidosis } \\
\text { diabética }\end{array}$ & $\begin{array}{c}\text { OR: 0,03 (IC } 95 \%: \\
0,00 \text { a } 685,60)\end{array}$ & \\
\hline
\end{tabular}

crecimiento a 2045 del $62 \%$ en países con economías emergentes (3). En el mundo se intenta pasar de una visión glucocéntrica, donde se busca el control de $\mathrm{HbA}_{1 c}$, a un interés por obtener mejores desenlaces clínicos en términos de resultados cardiovasculares y renales.

Hasta donde se conoce, esta es la primera revisión sistemática de estudios integrativos orientada específicamente a desenlaces cardiovasculares, renales y de seguridad en pacientes con DM2, que incluye la evidencia más reciente y de mejor calidad evaluada con la herramienta AMSTAR-2 modificado.

Los iSGLT2 parecen ser efectivos en la reducción del riesgo de mortalidad cardiovascular, de mortalidad por todas las causas y de admisión hospitalaria por insuficiencia cardíaca en comparación con el cuidado estándar; sin embargo, este resultado debe ser interpretado teniendo en cuenta que la población estudiada en los ensayos clínicos fue mayoritariamente población con enfermedad cardiovascular establecida y el método de integración de los estudios fue a través de comparaciones indirectas.

Respecto al desenlace renal, todos los ensayos tienen como referencia principal los estudios primarios de las tres moléculas de las que se disponen: empagliflozina, canagliflozina y dapagliflozina, que en total suman cerca de 38000 pacientes. La evidencia sugiere que los iSGLT2 reducen la progresión de 
la enfermedad renal al enlentecer el deterioro de la eTFG en seguimientos superiores a 52 semanas; además, en períodos de seguimiento diferentes se observó una disminución en la relación albuminuria-creatinuria, el riesgo de microalbuminuria, macroalbuminuria, progresión de la nefropatía y progresión a la enfermedad renal en estadio final. Tanto los estudios con dapagliflozina como empagliflozina incluyeron menores proporciones de pacientes con ERC en estadio 3A o superiores (TFG $<60 \mathrm{~mL} / \mathrm{mL} / 1,72 \mathrm{~m}^{2}$ ) y solo el estudio CREDENCE, en el que sí se tuvo como propósito el desenlace renal puro, se tuvo como criterio de inclusión la proteinuria con índice albuminuria-creatinuria $>300 \mathrm{mg} / \mathrm{g}$; por tanto, se considera que aunque hay una tendencia a favor de la intervención, generalizar el uso de estos medicamentos en todos los pacientes con enfermedad renal diabética no necesariamente agrega un beneficio. Igualmente, las poblaciones incluían en principio a los pacientes fuera de las metas de control metabólico y larga evolución de la enfermedad, pacientes con enfermedad cardiovascular conocida; por tanto, en nuestro medio las indicaciones deberían racionalizarse para aplicarse a este grupo de pacientes; es decir, a los que tengan enfermedad cardiovascular o alto riesgo, proteinuria establecida y mal control metabólico; y siempre acompañadas de las intervenciones ya conocidas como inhibidores de la enzima convertidora de angiotensina (IECA), los antagonistas del receptor de angiotensina 2 (ARA2) y los cambios en el estilo de vida.

Hasta el momento, las herramientas conocidas para ralentizar el deterioro en la ERC fueron el uso de los IECA y ARA-2. Los iSGLT2 se están forjando como una promisoria herramienta para contextualizar el impacto. A partir de los hallazgos de Neuen y colaboradores, estimamos la frecuencia de ocurrencia del desenlace compuesto renal, del cual se encontró que, en el grupo de pacientes que recibió iSGLT2, la frecuencia del desenlace de progresión de la enfermedad renal en estadio final fue $0,86 \%$ frente al 1,32 \% en el comparador; para el desenlace compuesto de pérdida de la función renal, enfermedad renal en estadio final o muerte por causa renal fue $2,5 \%$ frente a $4,3 \%$ a favor de iSGLT2; estos datos corroboran la importancia de incluir estas moléculas en la práctica clínica, pero se debe tener cautela con los análisis descritos antes.

Respecto al desenlace de seguridad, se sugiere que los iSGLT2 tienen menor riesgo de eventos de hipoglucemia al compararlos principalmente con sulfonilureas e insulina, pero hay mayor frecuencia de infección del tracto genitourinario. En la revisión, los otros desenlaces de seguridad que incluyen fracturas, amputación, pancreatitis y cetoacidosis diabética no se encontraron diferencias significativas entre los iSGLT2 y los comparadores.

Las limitaciones, a saber, corresponden al diseño metodológico empleado en el que la búsqueda de literatura se realizó en solo 2 bases de datos, aunque se intentó ampliar con la consulta con expertos clínicos y que la selección estuvo a cargo de un único evaluador; además, se reconocen las limitaciones debidas a la herramienta de calidad empleada, teniendo en cuenta que es una versión reciente con altos estándares de reporte que implicó la exclusión de 13 estudios. Es necesario hacer un llamado a los generadores de evidencia en el sentido de que, a pesar de existir una gran cantidad de evidencia en el tema y teniendo en cuenta que se encontraron 24 revisiones sistemáticas, 13 debieron ser excluidas por calidad. Aunque una parte se justifica por la herramienta empleada, es cierto que la falta de reporte de protocolo $a$ priori es un criterio que, incluso desde versiones previas de la herramienta, se ha requerido y aparentemente no se ha incluido de manera efectiva.

Los hallazgos no concluyentes o inconsistentes entre los estudios en algunos de los desenlaces pueden deberse a que los estudios primarios no fueron diseñados inicialmente para contrastar hipótesis de desenlaces renales y cardiovasculares.

En conclusión, la evidencia relacionada con la efectividad de iSGLT2 en comparación con el cuidado estándar sugiere beneficios en los desenlaces de mortalidad cardiovascular, mortalidad por todas las causas, en admisión hospitalaria por insuficiencia cardíaca, riesgo de microalbuminuria, macroalbuminuria, pérdida de la función renal, estadio terminal, muerte por enfermedad renal e incidencia de hipoglucemia.

Finalmente, los autores de estas revisiones sistemáticas de la literatura recomiendan el desarrollo de estudios primarios que permitan establecer el efecto y seguridad de los iSGLT2 sobre los desenlaces cardiovasculares y mejorar el reporte de revisiones sistemáticas de la literatura.

\section{Implicación en la práctica clínica}

Esta revisión puede orientar la práctica clínica en pacientes con DM2 y enfermedad cardiovascular establecida o con riesgo de enfermedad renal con el objetivo de mejorar los desenlaces cardiovasculares y renales.

\section{Agradecimientos}

Los autores agradecen a la comisión de diabetes por el arduo trabajo realizado.

\section{Conflictos de interés}

Todos los autores declaran no tener conflictos de interés.

\section{Fuentes de financiación}

Este trabajo se realizó en el marco de la comisión de diabetes de Keralty, bajo la coordinación del IGEC. No hubo financiación adicional para su desarrollo. 


\section{Referencias}

1. Informe mundial sobre la diabetes. Resumen de orientación [internet]. Organización Mundial de la Salud; 2016 [citado 08 de noviembre de 2019] Disponible en: https://apps.who.int/iris/bitstream/handle/10665/204877/WHO_NMH_NVI_16.3_spa.pdf;jsessionid=AF6B3407 5D78F05440BCD7468DEA6FE2?sequence $=1$

2. Findings from the Global Burden of Disease Study 2017. Seattle, WA: IHME; 2018.

3. Herrera AB. Análisis de Situación de Salud (ASIS) Colombia, 2018. Ministerio de salud y Protección Social; 2019.

4. Boletín de información técnica especializada de la cuenta de alto costo. CAC. 2018;4(17):1-6.

5. Guía de práctica clínica para el diagnóstico, tratamiento y seguimiento de la diabetes mellitus tipo 2 en la población mayor de 18 años. Bogotá: Ministerio de Salud y Protección Social de Colombia; 2016.

6. Shea BJ, Reeves BC, Wells G, Thuku M, Hamel C, Moran J, et al. AMSTAR 2: a critical appraisal tool for systematic reviews that include randomised or non-randomised studies of healthcare interventions, or both. BMJ. 2017;358:j4008.

7. Neuen BL, Young T, Heerspink HJL, Neal B, Perkovic V, Billot L, et al. SGLT2 inhibitors for the prevention of kidney failure in patients with type 2 dia- betes: a systematic review and meta-analysis. Lancet Diabetes Endocrinol. 2019;7(11):845-854

8. Bae JH, Park EG, Kim S, Kim SG, Hahn S, Kim NH. Effects of Sodium-Glucose Cotransporter 2 Inhibitors on Renal Outcomes in Patients with Type 2 Diabetes: A Systematic Review and Meta-Analysis of Randomized Controlled Trials. Sci Rep. 2019;9(1):13009.

9. Liu XY, Zhang N, Chen R, Zhao JG, Yu P. Efficacy and safety of sodiumglucose cotransporter 2 inhibitors in type 2 diabetes: a meta-analysis of randomized controlled trials for 1 to 2years. J Diabetes Complications. 2015;29(8):1295-303.

10. Xu L, Li Y, Lang J, Xia P, Zhao X, Wang L, et al. Effects of sodium-glucose co-transporter 2 (SGLT2) inhibition on renal function and albuminuria in patients with type 2 diabetes: a systematic review and meta-analysis. PeerJ. 2017;5:e3405.

11. Hussein H, Zaccardi F, Khunti K, Seidu S, Davies MJ, Gray LJ. Cardiovascular efficacy and safety of sodium-glucose co-transporter-2 inhibitors and glucagon-like peptide-1 receptor agonists: a systematic review and network meta-analysis. Diabet Med. 2019;36(4):444-452. 


\section{Sy

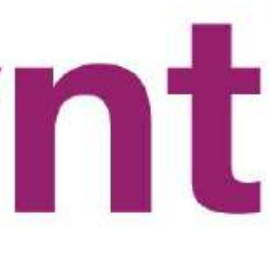 \\ hroid

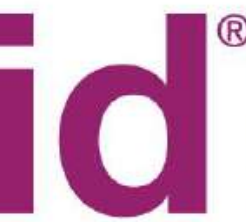 \\ Levotiroxina Sódica}

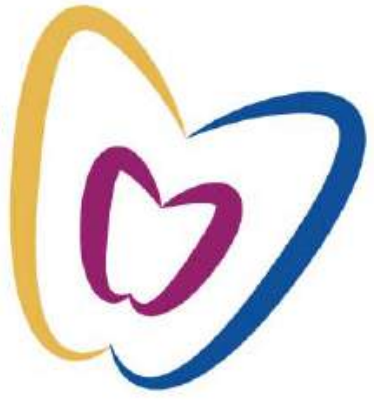

\section{PALPAR EL CUELLO Y EVALUAR LA TSH, PUEDE ALERTAR SOBRE ALGÚN TRASTORNO TIROIDEO ${ }^{(1,2,3)}$}

CUELLOS

QUE CAUTIVAN...

MARCA DE REFERENCIA EN COLOMBIA

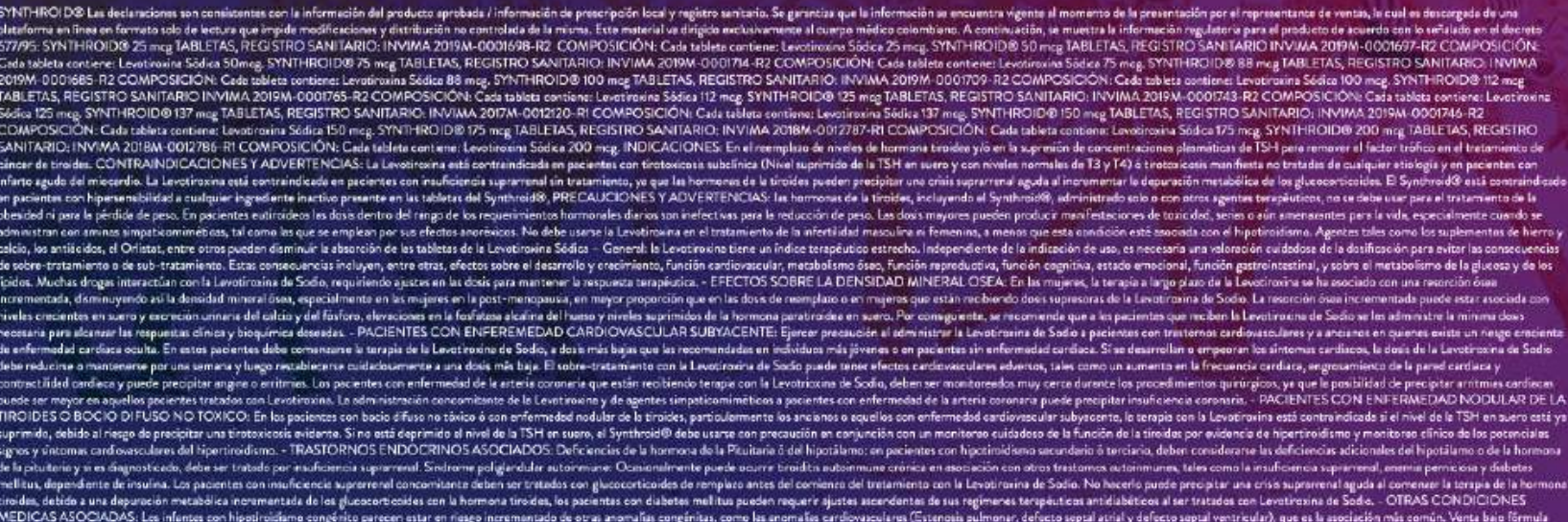

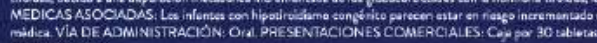

1. Deverit:

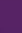

